\title{
Control of Pharmacy Degree Heat
}

\author{
Hanadi Idriss Yahya Abdalla ${ }^{1}$, ELtahir Mohamed Hussein ${ }^{2}$ \\ ${ }^{1}$ Faculty of Engineering, Alneelain University, Khartoum, Sudan \\ ${ }^{2}$ College of Engineering, Sudan University of Science and Technology (SUST), Khartoum, Sudan
}

\begin{abstract}
Some sensitive systems need a specific temperature to Maintaining the quality and effectiveness a pharmacy contents for example. Need pharmacy to store the pharmaceutical and medical appliances at a certain temperature, temperature inside the pharmacy must be controlled. So, I decided to construct a system that controls the cooling devices used in pharmacies. The system works by increasing the speed of the cooling device when the temperature increases inside the pharmacy. The system also decreases the speed of the cooling device when the temperature decreases inside the pharmacy. The proposed system gives acceptable result in the real test.
\end{abstract}

Keywords: Temperature Sensor, Microcontroller, Relay

\section{Introduction}

The system works to control the speed of the cooling device by temperature. Used micro controlled makes the system more flexible in operation and reduces the size of the circle and gives the possibility to control the operation and stop the system elements. Control by the temperature used sensor temperature to measure the environmental temperature form physical and then passed to the microcontroller in the form of an electrical signal, controller analyzes the signal and make a decision in the form of orders as a result of the analysis and send commands to the rest of the system components of the screen and relay For their actual benefit from micro controller be combined with other elements to create a system utilized it. The controller does not give more effort out of 5 volts in this system I want to control the speed of the cooling device is $220 \mathrm{~V}$ so I added relay to become a mediator between the controller and the cooling device, which we want leadership, Figure 1 illustrates the components of the system:

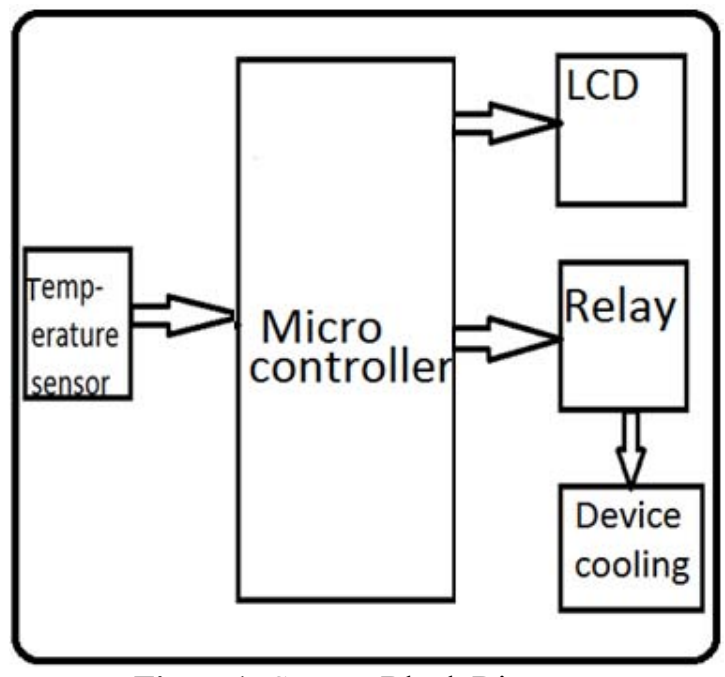

Figure1: System Block Diagram

\section{Temperature Sensor}

The temperature sensor acts by sensing the temperature degrees inside the pharmacy. The sensor used in this system is LM35, The sensor Lm35 characterized by accurately measuring at 0.5 which is good for most applications, and has a feeding effort ranged from $4 \mathrm{v}$ to $30 \mathrm{v}$, and contend with temperatures ranging from 55 below zero to 150 degrees above zero, and that the relationship completely written between temperature and output of sensor, senses the temperature in its analog form Then transfers it to the microcontroller via port A. The LM35 is an integrated circuit sensor that can be used to measure temperature with an electrical output proportional to the temperature (in Celsius) the scale factor is $10 \mathrm{mV} /{ }^{\circ} \mathrm{C}$.

\section{Microcontroller}

The microcontroller acts by controlling the speed of the cooling device after converting the analog signals of the temperature to digital signals and gives us the possibility to control by operation and stop the other elements by times up to fractions of a second. The microcontroller used in the system is form the type Atmega16.

\section{Realy}

The system is connected with the fan where operated at a certain given temperature, then separate it at a certain degree, but controller cannot provide the voltage and current suitable for the operation of the fan or any device that works with more than 5 volts and more than 25 Mile Am so such that we use the Linking circle to connect with systems that are low voltage and current with high-voltage systems without any system affects the other. In this system used relay to connected microcontroller is low Dc volts with fan is high Ac volts.

\section{Display Screen}

The display screen used in this system is LCD $2 * 16$. The advantage of using the LCD said energy consumption and this is good for applications that use small batteries as a source of effort and have a high accuracy in the show and the writing has a backlight, which allows them to see writing in the dark. The Temperature degree and the speed of the Fan are displayed in LCD, is connected to port B of the microcontroller. 


\section{International Journal of Science and Research (IJSR) \\ ISSN (Online): 2319-7064}

Index Copernicus Value (2015): 78.96 | Impact Factor (2015): 6.391

\section{Cooling Device}

The cooling device used in this system is a Fan 220 volts connected to the relay and the voltage supply directly.

\section{Previous Study}

Electrical and Electronic Engineering, Explanation of Control Project in temperature an environment, Ala Alden Habeb, 16/1/2014

To the controller to monitor the rest of the elements in the electronic circuit or the environment, you need to sensors for environment monitor and then give out commensurate with the environment conditions, for example, when we want to monitor the temperature of the environment around the controller need to temperature sensor measures the temperature and then the passing to the microcontroller in the form of an electrical signal. Temperature sensor can measure the temperature in the center surrounding and it is advantage a good reliability which has a $0.5^{\circ} \mathrm{C}$ error ratio that is the temperature at which it will give us can increase or decrease by half a degree Celsius only, the nature of his work that when we give in income 5 volt Van narrated increase by $10 \mathrm{mi}$ volts per degree Celsius which he at one degree Celsius will be narrated by $10 \mathrm{mi}$ volts This increase is linear. after deliver Temperature sensor became our effort outside of the sensor represents the temperature will take this effort and introduce it to accurately controlled, which will make some processors and then make decisions as a result of these processors, but we have a problem delicate came out that's a variation effort is considered an analogue and controlled the exact signal does not understand the reference analogue is only understands the digital signal if in order to get them to communicate with some of the communicating certainly do not need an interpreter to come, including in this case, we found that the translator and any calls ADC converter from Analog-todigital Converter, Fortunately for us, the controlled that we use has a nice feature which it contains a converter from Analog Digital Indoor any will not need an external a converter. So that we connect the controller so that he can work and perform the functions required of it must be some connections, without it cannot be controlled that never works and is first connected to the controller with voltage source positive and negative terminal if the first basic connection to the precise controller is working power source. Second connection is essential that when we want to re-run the exact controller (reset) make income on the party MCLR 0 volts who shall re-run strictly controlled. Third ext is Crystal or oscillator and an electronic element is giving us the impulses or vibrations of a certain frequency is necessary to organize the work in the controlled, the controller associates all of the operations of these pulses each process or processing performed within the controller are in accordance with those coming from Crystal vibrations. After connected all the necessary connections controller receives the signal from the sensor and the necessary treatments the results of this treatment will show an output in certain devices in this case are the fan and the screen.

\section{The Proposed System}

The system as an executive director of the temperature where the plan to give it to manage temperature by programming Microcontroller, Then the system monitors the temperature If the temperature exceeds a predetermined degree of the programming reference that it shall run the fan and increase of the fan speed when the temperature increase and the decreases the speed of the fan if the temperature decrease .and automatically stop the fan to electrical economize when the temperature decrease the degree of specific reference in programming. Below the circuit system presentation:

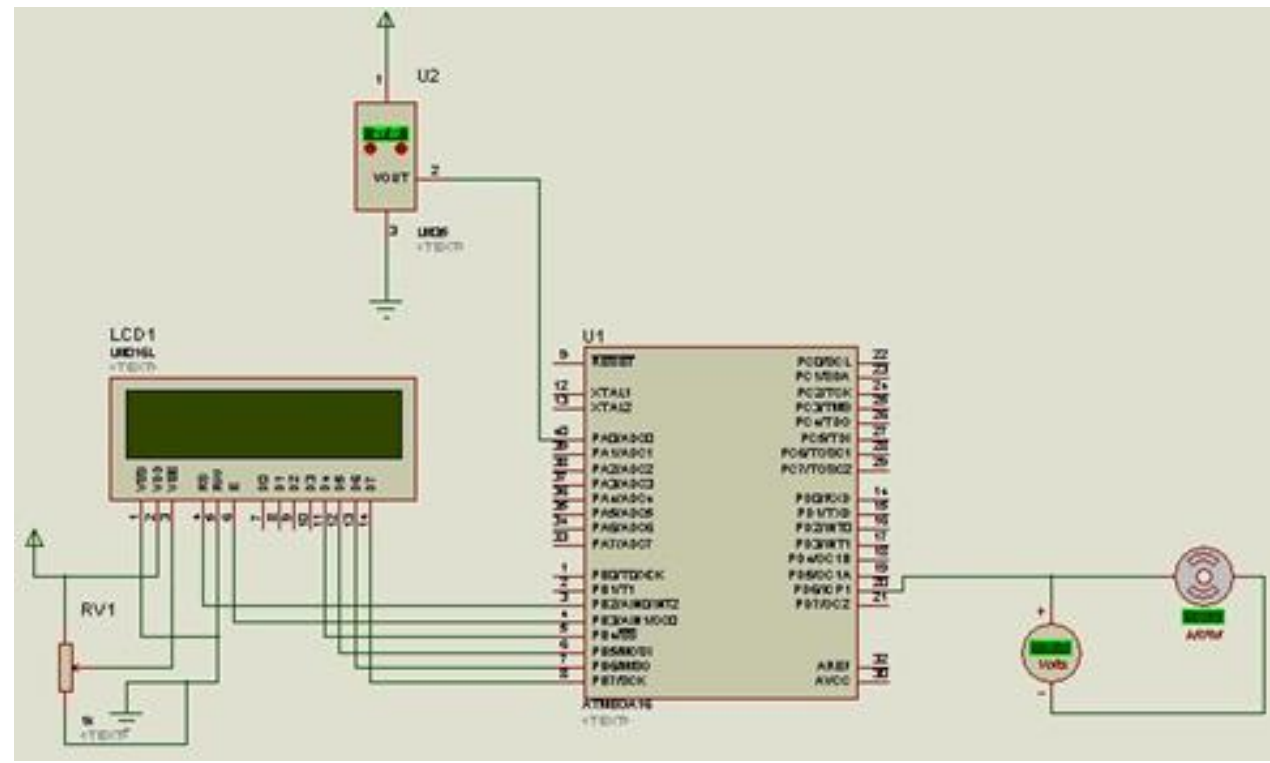

Figure 2: Circuit System Presentation 


\section{International Journal of Science and Research (IJSR)}

ISSN (Online): 2319-7064

Index Copernicus Value (2015): 78.96 | Impact Factor (2015): 6.391

Table 1: shows the pins used to connect the system components

\begin{tabular}{|l|l|l|}
\hline \multicolumn{3}{|c|}{ Atmega16 } \\
\hline PA0 (ADC0) & ADC Channel 0 & I/O PORTA, Pin 0 \\
\hline (INT2/AIN0) PB2 & I/O PORTB, Pin 2 & $\begin{array}{l}\text { AIN0: Analog Comparator Positive I/P } \\
\text { INT2: External Interrupt 2 Input }\end{array}$ \\
\hline (OC0/AIN1) PB3 & I/O PORTB, Pin 3 & $\begin{array}{l}\text { AIN1: Analog Comparator Negative I/P } \\
\text { OC0 : Timer0 Output Compare Match Output }\end{array}$ \\
\hline (SS) PB4 & I/O PORTB, Pin 4 & $\begin{array}{l}\text { In System Programmer (ISP) } \\
\text { Serial Peripheral Interface (SPI) }\end{array}$ \\
\hline (MOSI) PB5 & I/O PORTB, Pin 5 & In System Programmer (ISP) \\
\hline (MISO) PB6 & I/O PORTB, Pin 6 & Serial Peripheral Interface (SPI) \\
\hline (SCK) PB7 & I/O PORTB, Pin 7 & In System Programmer (ISP) \\
\hline (RXD) PD0 & I/O PORTD, Pin 0 & USART Serial Communication Interface \\
\hline (ICP) PD6 & I/O PORTD, Pin 6 & PWM Channel Outputs \\
\hline AREF & Analog Reference Pin for ADC & Analog Reference Pin for ADC \\
\hline AVcc & Voltage Supply=Vcc for ADC & LCD \\
\hline \multicolumn{3}{|l|}{} \\
\hline V EE & Contrast adjustment; through a variable resistor \\
\hline Register Select & Selects command register when low; and data register when high \\
\hline Enable & Sends data to data pins when a high to low pulse is given \\
\hline DB4 & data pins \\
\hline DB5 & data pins \\
\hline DB6 & data pins \\
\hline DB7 & data pins \\
\hline Read/write & Low to write to the register; High to read from the register \\
\hline \multicolumn{3}{|l|}{} \\
\hline V cc & Supply voltage; 5V (+35V to -2V) \\
\hline Output & Output voltage (+6V to -1V) \\
\hline Ground & Ground (0V) \\
\hline
\end{tabular}

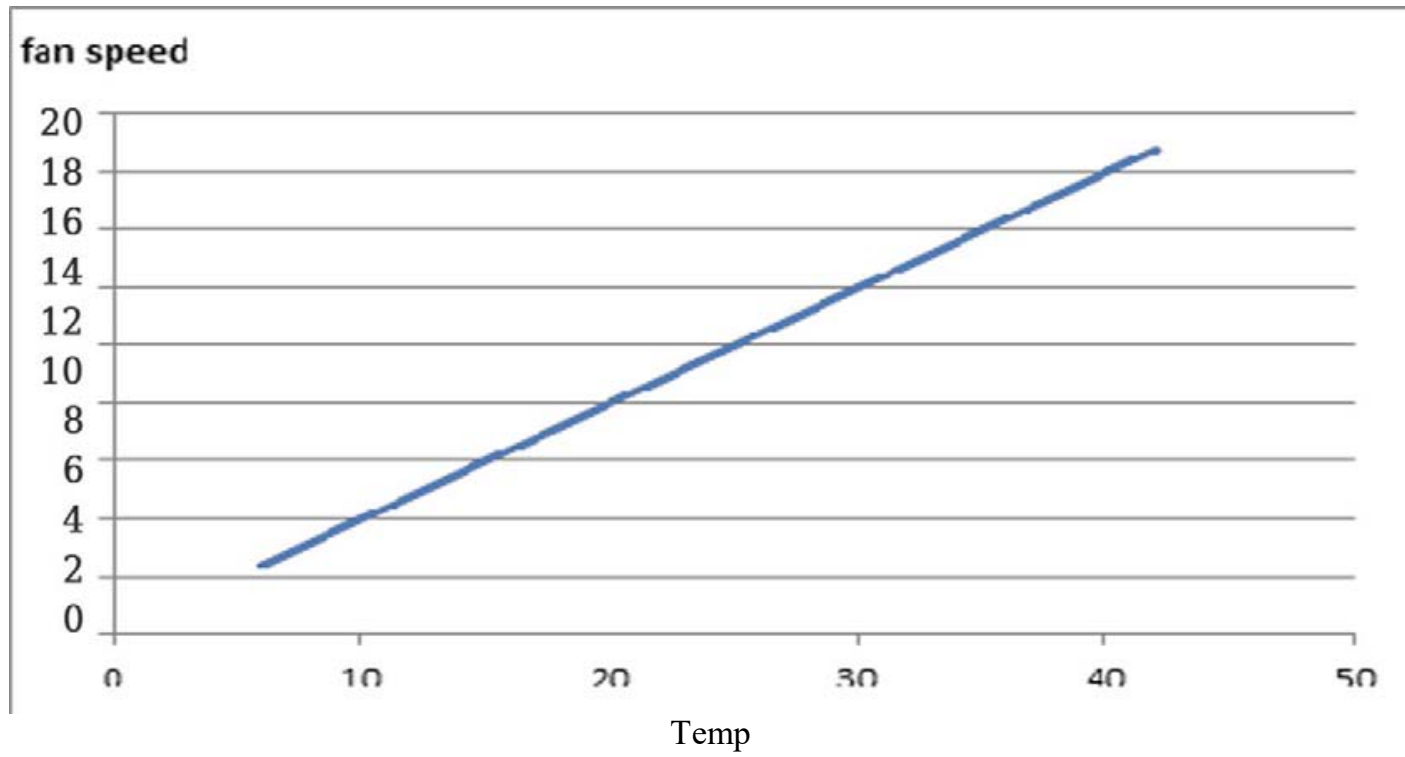

Figure 3: Chart

\section{Results}

1) The system performs management plan literally in accordance with the orders limited in programming, the following are some readings screen when the system was operating effectively under different temperature, Figure 3.

2) The sensor $\operatorname{Lm} 35$ does not require any external calibration and its output commensurate with the temperature.
3) When you connect the fan with circuit connectivity is better to have a separate source voltage of the source of voltage of the microcontroller.

4) In the case of the amendment on the Circuit system we are not to change the connections, but we just amending the programming.

\section{Conclusions}

1) Possible operation of the system with other cooling devices and can also add some control systems, such as fuzzy logic.

Volume 6 Issue 1, January 2017

www.ijsr.net

Licensed Under Creative Commons Attribution CC BY 


\section{International Journal of Science and Research (IJSR) \\ ISSN (Online): 2319-7064}

Index Copernicus Value (2015): 78.96 | Impact Factor (2015): 6.391

2) In conclusion, the system can control the speed of the fan inside the pharmacy, based on the temperature inside that pharmacy and it does not need a key to increase or decrease the speed of the fan.

\section{References}

[1] www.dbaasco.com

[2] www.alldatasheet.com/Lm35

[3] www.eletorial.com

[4] www.eeecb.com

[5] www.atmel.com

[6] www.arabteam2000-forum.com

[7] www.olightek.com

[8] https://ar.wikipedia.org

[9] www.electronics-tutorials.ws

[10]www.eletorial.com , Electrical and Electronic Engineering, Explanation of Control Project in temperature an environment, 16/1/2014

[11] Microcontroller, Engineer Abdul Humid Bassiouni, last modified version 23/2/2013

[12]Book of Electronic Sensors, Source: General Organization for Technical Education and Vocational Training

[13] Relay Book, E-library to download and read comic books; add the book in 11/5/2008 